\title{
PENENTUAN DISTRIBUSI TIPE AWAN DI PROVINSI RIAU MENGGUNAKAN CITRA SATELIT MTSAT IR1
}

\author{
Saraswati Dewi
}

\begin{abstract}
Intisari
Penentuan distribusi tipe awan berdasarkan diagram temperatur kecerahan (TBB) perbedaan TBB dilakukan dengan menggunakan data citra satelit MTSAT IR1 dan IR2 pada bulan Januari dan Maret 2014 di 4 (empat) titik kajian di Provinsi Riau. Terdapat 6 (enam) tipe awan yang dikategorikan dalam diagram TBB-DT antara lain awan dingin dengan ketebalan optik besar (tipe awan Cumulonimbus/Cb), awan hangat dengan ketebalan optik besar (tipe awan Cumulus/Cu atau Stratocumulus/Sc), awan dingin dengan ketebalan optik kecil (tipe awan Cirrus/Ci yang cukup padat atau dense), awan hangat dengan ketebalan optik kecil (tipe awan Ci), serta awan tipe $N$ yang merupakan tipe awan tipis di level rendah.

Dari seluruh data yang ada dalam pada bulan Januari 2014 dan Maret 2014, distribusi awan di daerah kajian didominasi oleh tipe awan Cirrus (Ci tipis, Ci tebal, dan Ci solid). Karakteristik wilayah Riau yang cenderung kering di bulan Januari maupun Maret 2014 mempengaruhi pertumbuhan awan di daerah tersebut dan kondisi cuaca didominasi oleh cuaca cerah. Dari perbandingan yang dilakukan antara hujan dengan tipe awan di 4 (empat) titik kajian, penentuan jenis awan penghasil hujan tidak dapat dilakukan hanya dengan mengambil data TRMM dan data TBB di suatu titik karena tidak menunjukkan adanya hubungan antara hujan dengan tipe awannya. Hujan yang jatuh di titik kajian bisa jadi tidak berasal dari awan yang berada tepat di atasnya karena faktor angin.
\end{abstract}

Kata kunci : awan, satelit, temperatur kecerahan

\begin{abstract}
Determination of cloud type distribution based on the brightness temperature (TBB) - temperature differential image (DT) has been done using MTSAT IR1 and IR2 image data on January and March 2014 at 4 (four) point studies. There are 6 (six) cloud types categorized by the TBB-DT diagram: optically thick cold cloud (Cb type), optically thick warm cloud (Cu/Sc type), optically thin cold cloud (thin Ci type/dense Ci), and N-type which is low level thin clouds.

Based on all of the data from January and March 2014, cloud distribution on the field of study was dominated by Ci type clouds (thin $\mathrm{Ci}$, thick $\mathrm{Ci}$, and dense Ci). Dry characteristics of the area of Riau province influenced cloud development over the area and was dominated with fair weather. From the comparison between rain events and the cloud type, rain cloud determination cannot be done with only data point of TRMM rainfall data and MTSAT TBB data because it didn't represent the relationship between rain events and it's cloud type. Rain which fall on point study might not come from the clouds right on it due to the wind factor.
\end{abstract}

Keywords: cloud, satellite, brightness temperature

\section{PENDAHULUAN}

Setiap daerah memiliki karakteristik wilayah yang berbeda-beda yang mempengaruhi kondisi cuaca lokalnya termasuk karakteristik awannya. Studi karakteristik awan perlu dilakukan untuk mengetahui bagaimana distribusi tipe awan di suatu daerah baik di bulan kering maupun di bulan basah. Studi ini juga bermanfaat bagi kegiatan teknologi modifikasi cuaca.
Studi tentang awan saat ini dapat dilakukan dengan memanfaatkan citra satelit. Beberapa satelit Meteorologi memberikan data real-time dengan resolusi tinggi dan dapat diunduh dengan mudah. Melalui citra satelit, tipe awan dapat dilihat dari temperatur kecerahannya. Temperatur kecerahan (TBB) merupakan pengukuran dari radiasi termal yang diemisikan suatu benda, dalam hal ini adalah awan. 
Tujuan dari studi ini adalah untuk melihat bagaimana populasi awan di beberapa titik kajian dengan melihat komposisi dari tipe-tipe awannya serta melihat hubungan hujan yang terjadi dengan tipe awannya.

Teknik yang digunakan dalam melihat komposisi awan di daerah kajian adalah dengan menggunakan metode yang dikembangkan oleh Inoue (1987a) menggunakan citra kanal infrared satelit MTSAT yang mengklasifikasikan awan sebanyak beberapa tipe antara lain awan dingin dengan ketebalan optik besar (tipe awan Cumulonimbus/Cb), awan hangat dengan ketebalan optik besar (tipe awan Cumulus/Cu atau Stratocumulus/Sc), awan dingin dengan ketebalan optik kecil (tipe awan Cirrus/Ci yang cukup padat atau dense), awan hangat dengan ketebalan optik kecil (tipe awan $\mathrm{Ci}$ ), serta awan tipe $\mathrm{N}$ yang merupakan tipe awan tipis di level rendah.

\section{DATA}

Data yang digunakan dalam studi ini adalah data dari satelit MTSAT yang dioperasikan oleh Japan Meteorological Agency (JMA) dengan resolusi spasial $1 \mathrm{~km} \times 1$ $\mathrm{km}$ untuk citra visible dan $4 \mathrm{~km} \times 4 \mathrm{~km}$ untuk citra infrared (IR) serta memiliki resolusi temporal 1 jam. Data satelit MTSAT ini dapat diunduh secara gratis di http://weather.is.kochiu.ac.jp/sat/ALL/ dengan format data *.pgm. Dalam enentukan tipe awan pada studi ini, data yang digunakan adalah citra infrared kanal 1 (IR1) dengan panjang gelombang $10.3 \mu \mathrm{m}-$ $11.3 \mu \mathrm{m}$ dan citra infrared kanal 2 (IR2) dengan panjang gelombang $11.5 \mu \mathrm{m}-12.5 \mu \mathrm{m}$. Data temperatur kecerahan (TBB) pada titik-titik kajian diperoleh dari data kanal IR1 dan IR2 yang sudah dikonversi menjadi format *. grb.

Sebagai data penunjang, data curah hujan dari satelit Tropical Rainfall Measuring Mission (TRMM) juga digunakan dalam studi ini untuk membandingkan kejadian hujan dengan tipe awan penghasil hujannya. Data TRMM yang digunakan memiliki resolusi spasial $11.1 \mathrm{~km} \times$ $11.1 \mathrm{~km}$ serta resolusi temporal 1 jam dan dapat diunduh dari ftp://hokusai.eorc.jaxa.jp dengan format *.dat. Data kelembapan relatif rata-rata diperoleh dari http://www.esrl.noaa.gov/psd/data/gridded/ dengan format ${ }^{*}$.nc

\section{METODOLOGI}

Berdasarkan metode (Inoue, 1987a), tipetipe awan diklasifikasikan dengan temperatur kecerahan (TBB) dari kanal IR1 dan perbedaan TBB dari kanal IR1 dan IR2 (Inoue, 1989). Perbedaan TBB (DT) merupakan indikator yang baik dalam membedakan awan berdasarkan ketebalan optik. DT dapat diperoleh dari TBB kanal IR1 dikurangi TBB kanal IR2 (DT=TBB $\left.\left.\right|_{\mathbb{R} 1}-\mathrm{TBB}_{\mathrm{IR} 2}\right)$. Awan dengan ketebalan optik besar akan memiliki nilai DT yang kecil sedangkan awan dengan ketebalan optik kecil akan memiliki nilai DT yang besar. Nilai threshold DT untuk awan tebal adalah $1^{\circ} \mathrm{C}$ dan nilai threshold TBB untuk awan tebal adalah $-20^{\circ} \mathrm{C}$ (Inoue, 1989). Dalam penelitian terdahulu ditentukan pula nilai threshold DT untuk clear sky yaitu $2.5^{\circ} \mathrm{C}$ dan $22^{\circ} \mathrm{C}$ untuk threshold TBB-nya. Diagram klasifikasi tipe awan disajikan dalam Gambar 1 yang masingmasing kotaknya merepresentasikan tipe awan berbeda.

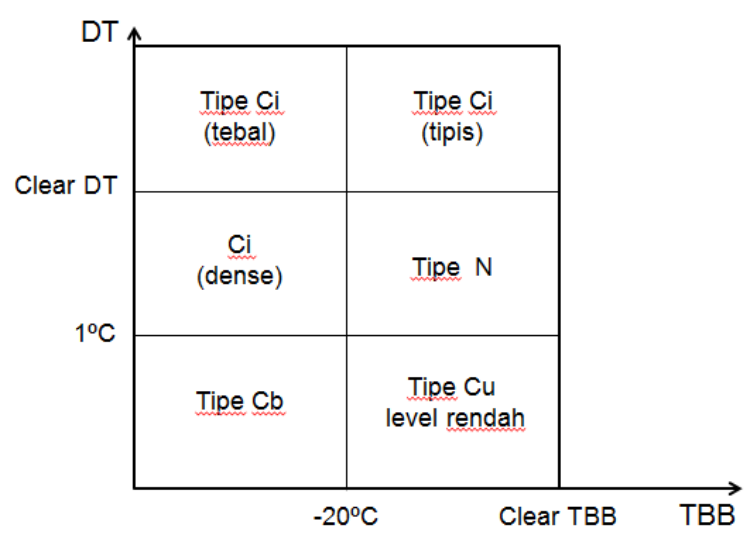

Gambar 1. Diagram klasifikasi tipe awan (Inoue, 1989)

Diagram TBB-DT pada Gambar 1 selanjutnya akan dijadikan dasar dalam klasifikasi awan di daerah beberapa titik kajian yang terdiri dari Pekanbaru (Lat. 0.517, Lon. 101.448), Pulau Rupat (Lat. 1.892, Lon. 101.598), Kep. Meranti (Lat. 1.165, Lon. 102.344), dan Pelalawan (Lat. 0.45, Lon. 102.08).

\section{HASIL DAN ANALISIS}

Gambar 2 dan Gambar 3 merepresentasikan distribusi tipe awan di wilayah kajian pada bulan Januari 2015 dan Maret 2015 berdasarkan diagram TBB-DT. Persentase tipe awan didapat dari jumlah munculnya suatu tipe awan dibandingkan dengan jumlah total data yang ada dalam satu bulan (744 data di bulan Januari 2014 dan 672 data di bulan Maret 2014).

Pada bulan Januari 2014, kemunculan awan di 4 (empat) titik kajian didominasi tipe awan Cirrus (Ci), kemunculan awan $\mathrm{Ci}$ tipis dengan persentase rata-rata $45.40 \%$ (Tabel 1 ), tipe awan Cirrus solid (dense Ci) dengan persentase rata-rata $19.42 \%$, dan tipe awan $\mathrm{Ci}$ 
tebal dengan persentase rata-rata $13.07 \%$. Tipe awan $\mathrm{Ci}$ juga mengindikasikan kondisi cuaca yang cerah. Sama halnya dengan distribusi tipe awan di bulan Maret 2014, kemunculan awan pada bulan Maret 2014 didominasi oleh tipe awan Cirrus dengan persentase rata-rata kemunculan awan $\mathrm{Ci}$ tipis sebanyak $79.17 \%$, Ci tebal sebanyak $6.25 \%$, dan $\mathrm{Ci}$ padat/solid sebanyak $5.51 \%$.

Tipe awan Cumulonimbus (Cb) yang ditentukan dengan parameter DT kurang dari $1^{\circ} \mathrm{C}$ dan nilai temperatur kecerahan (TBB) kurang dari $-20^{\circ}$ memiliki persentase rata-rata kemunculan sebanyak $10.32 \%$ di bulan Januari 2014 dan 2.75\% di bulan Maret 2014. Awan tipe Cumulus di level rendah yang ditentukan dengan parameter DT kurang dari $1^{\circ} \mathrm{C}$ dan nilai temperatur kecerahan antara $-20^{\circ} \mathrm{C}$ hingga $22^{\circ} \mathrm{C}$ memiliki persentase rata-rata kemunculan $2.22 \%$ di bulan Januari 2014 dan $0.41 \%$ di bulan Maret 2014.

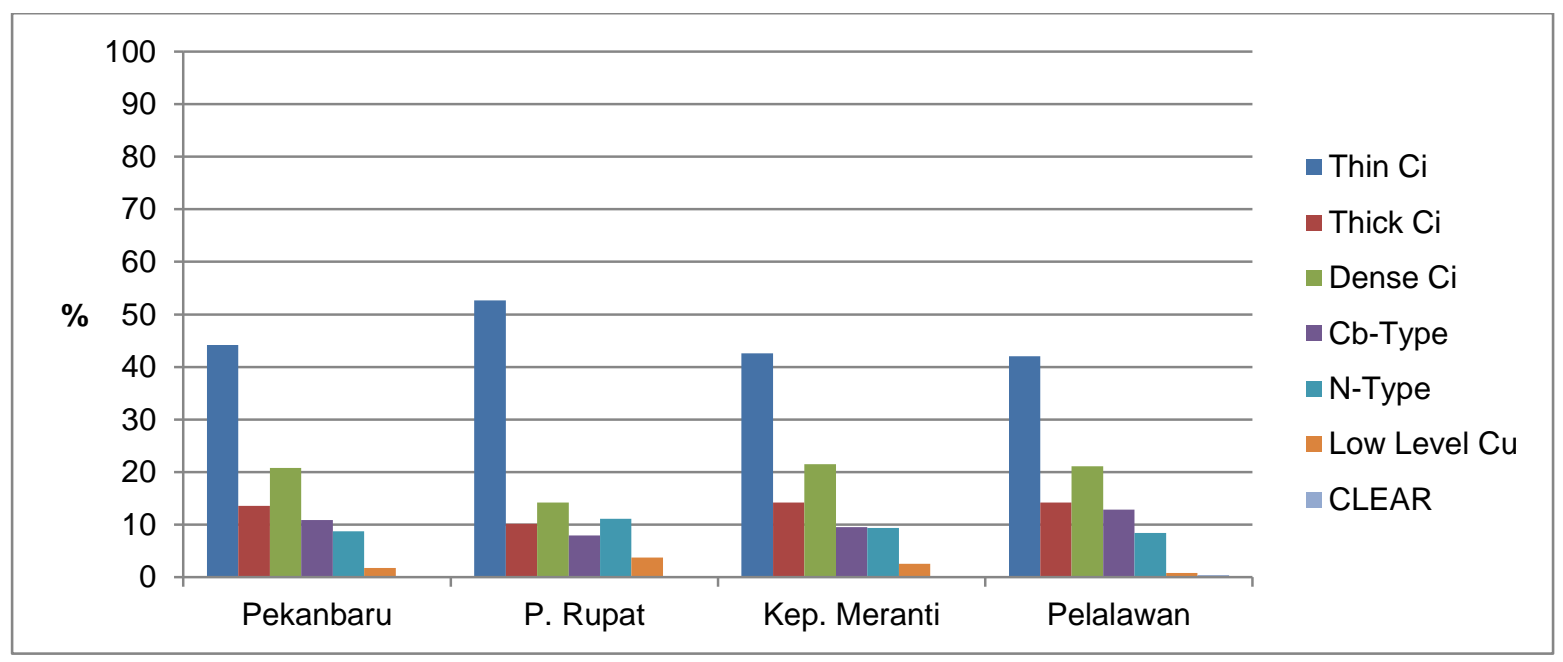

Gambar 2. Distribusi tipe awan di wilayah kajian pada bulan Januari 2014

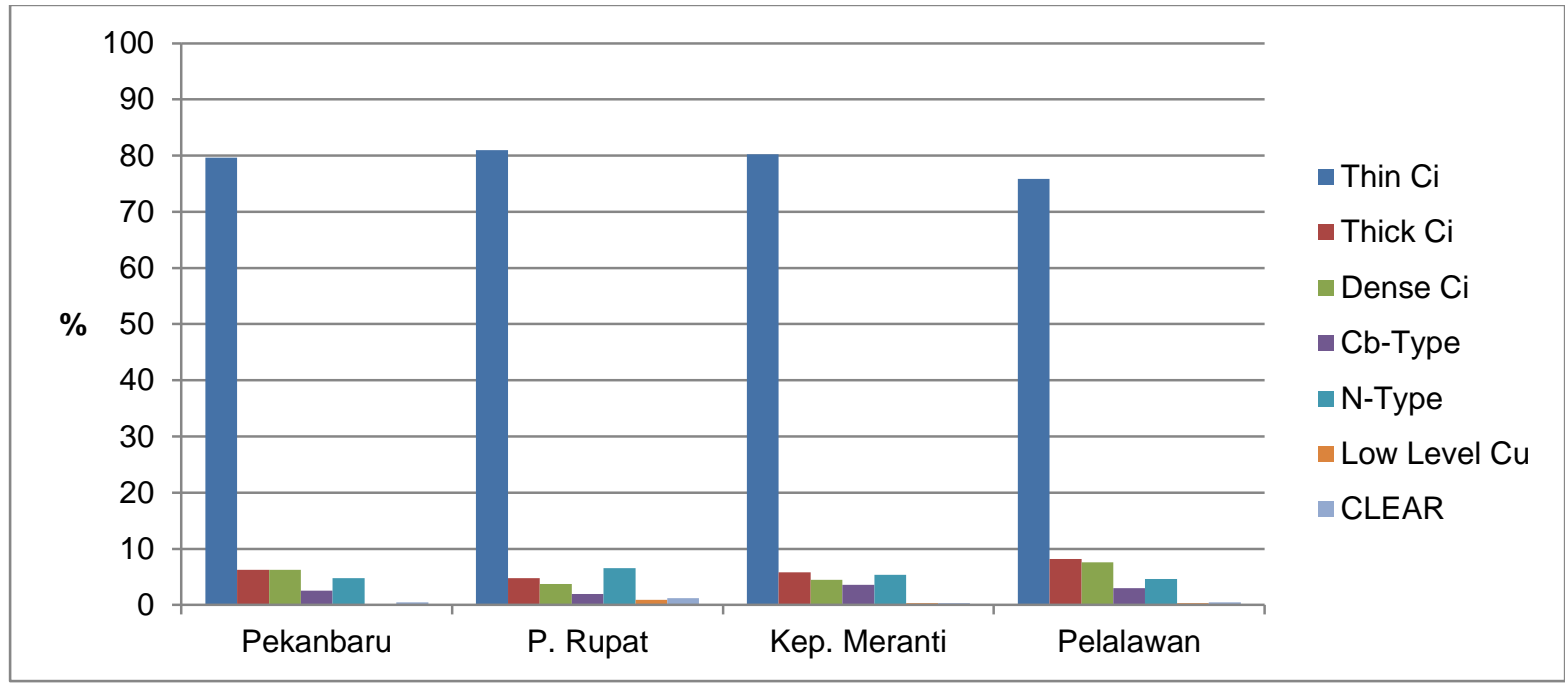

Gambar 3. Distribusi tipe awan di wilayah kajian pada bulan Maret 2014 
Tabel 1. Rata-rata tutupan awan di wilayah kajian

\begin{tabular}{|l|c|c|}
\hline \multicolumn{1}{|c|}{ Tipe } & $\begin{array}{c}\text { Januari } \\
\mathbf{2 0 1 4}\end{array}$ & $\begin{array}{c}\text { Maret } \\
\mathbf{2 0 1 4}\end{array}$ \\
\hline Ci tipis & $45.40 \%$ & $79.17 \%$ \\
\hline Ci tebal & $13.07 \%$ & $6.25 \%$ \\
\hline Ci padat & $19.42 \%$ & $5.51 \%$ \\
\hline Cb & $10.32 \%$ & $2.75 \%$ \\
\hline Cu rendah & $2.22 \%$ & $0.41 \%$ \\
\hline Tipe-N & $9.44 \%$ & $5.32 \%$ \\
\hline Cerah & $0.13 \%$ & $0.60 \%$ \\
\hline
\end{tabular}

Persentase kemunculan awan-awan rendah yang lebih kecil di bulan Maret 2014 dibandingkan dengan di bulan Januari 2014 disebabkan oleh kelembapan rata-rata daerah Riau yang relatif rendah di bulan Maret. Pada lapisan $850 \mathrm{mb}$, kelembapan relatif $(\mathrm{RH}) \mathrm{di}$ daerah Riau menunjukkan angka 70\%-80\% di bulan Maret 2014, lebih kering dibanding $\mathrm{RH}$ rata-rata pada bulan Januari 2014 yang sebesar $80 \%-90 \%$. Pada lapisan $700 \mathrm{mb}, \mathrm{RH}$ rata-rata di bulan Maret juga lebih rendah



(4a)



(4b) dibanding di bulan Januari 2014 yaitu sekitar 50\%-60\%. Pada lapisan $500 \mathrm{mb}, \mathrm{RH}$ rata-rata di wilayah Riau juga menunjukkan kondisi yang kering yaitu $60 \%-70 \%$ di bulan Januari 2014 dan 50\%-60\% di bulan Maret 2014. Keberadaan uap air yang lebih sedikit ini lah yang menyebabkan pertumbuhan awan di wilayah Riau cenderung terhambat di bulan Maret 2014 dan distribusi tipe awan di wilayah tersebut didominasi oleh awan-awan tinggi (Cirrus).

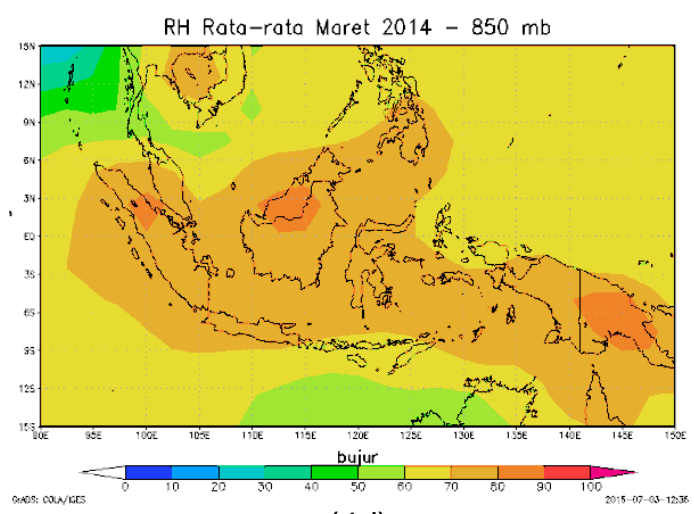

(4d)

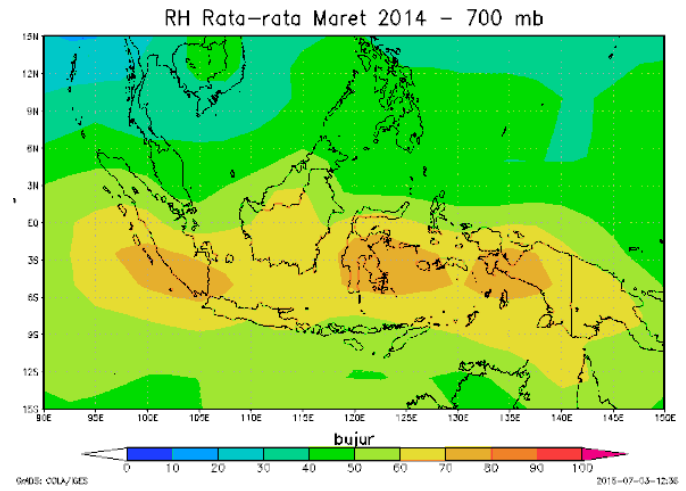

(4e) 
RH Rato-rata Januari 2014 - $500 \mathrm{mb}$

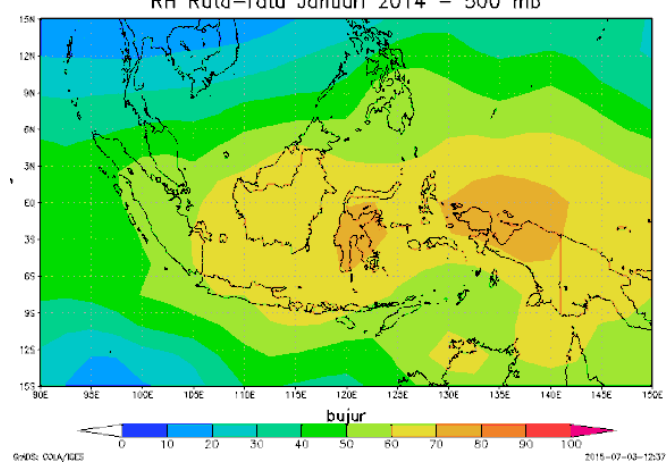

(4c)
RH Rata-rata Maret 2014 - $500 \mathrm{mb}$



(4f)

Gambar 4. Kelembapan relatif $(\mathrm{RH})$ di level $850 \mathrm{mb}, 700 \mathrm{mb}$, dan $500 \mathrm{mb}$ pada Januari 2014 dan Maret 2014

Perbandingan antara kejadian hujan yang terpantau satelit TRMM dengan nilai temperatur kecerahan awan (TBB) untuk mengetahui jenis awan apa yang menghasilkan hujan tersebut dilakukan dengan mengambil kejadian hujan dan data TBB pada saat ada kejadian hujan.



Gambar 5. Data kejadian hujan (garis hitam), DT (garis merah) dan TBB IR1 (garis hijau) bulan Januari 2015 di titik Pekanbaru untuk membandingkan kejadian hujan dan jenis awan penghasil hujannya.

Kejadian hujan di area arsir berwarna kuning no. 1 menunjukkan bahwa hujan terjadi dengan curah hujan sekitar 1 s.d $3 \mathrm{~mm}$ (data per-jam), DT bernilai lebih dari $1^{\circ} \mathrm{C}$ dan juga lebih dari threshold cerah sebesar $2.5^{\circ} \mathrm{C}$, nilai TBB IR1 bernilai kurang dari $-20^{\circ} \mathrm{C}$. Berdasarkan diagram TBB-DT, nilai-nilai tersebut menunjukkan bahwa awan pada saat itu adalah awan $\mathrm{Ci}$ tebal. Kemungkinan presipitasi yang berasal dari awan tinggi memang ada tetapi biasanya tidak sampai ke permukaan. Hal serupa terjadi pada kejadian hujan pada area arsir kuning no. 2 dengan curah hujan $15 \mathrm{~mm}$, DT di atas $2.5^{\circ} \mathrm{C}$ dan TBB IR1 di bawah $-20^{\circ} \mathrm{C}$ yang berarti awan $\mathrm{Ci}$ tebal. Berbeda dengan area arsir 1 dan 2, area arsir kuning 3 menunjukkan hujan sekitar $7 \mathrm{~mm}$ dengan DT di atas $2.5^{\circ} \mathrm{C}$ dan TBB IR1 yang bernilai lebih dari $20^{\circ} \mathrm{C}$ yang berarti kondisi clear/cerah. Nilai DT dan TBB IR1 yang bertepatan dengan kejadian hujan tidak bisa dijadikan patokan dalam menentukan awan penghasil hujannya. 


\section{KESIMPULAN}

Penentuan distribusi tipe awan di beberapa titik di Propinsi Riau telah dilakukan dengan berdasar pada diagram DT-TBB dengan waktu kajian di bulan Januari dan bulan Maret 2014. Hasil dari penentuan distribusi awan menunjukkan bahwa awan di bulan Januari maupun di bulan Maret 2014 di beberapa titik kajian di Prov. Riau didominasi oleh awan-awan $\mathrm{Ci}$ (Ci tipis, $\mathrm{Ci}$ tebal, maupun Ci padat) dengan persentase rata-rata $45.40 \%$ di bulan Januari 2014 dan $79.17 \%$ di bulan Maret 2014. Penentuan awan penghasil hujan dari data kejadian hujan dan TBB serta DT yang bertepatan dengan kejadian hujannya tidak bisa dijadikan dasar dalam menentukan awan penghasil hujan karena bisa saja hujan yang turun di titik tersebut tidak berasal dari awan yang berada tepat di atasnya karena faktor angin.

\section{DAFTAR PUSTAKA}

Choi, Y.-S., \& Ho, C.-H. (2009). Validation of Cloud Property Retrievals From MTSAT-1R Imagery Using MODIS Observations. Seoul National University.

Inoue, T. (1987a). A Cloud Classification with NOAA-7 Split Windows Measurements. Journal of Geophysical Research, 3991-4000.

Inoue, T. (1989). Feature of Clouds over Tropical Pacific during Northern Hemisphere Winter Derived from Split Window Measurements. Journal of the Meteorological Society of Japan, 621637.

Prabowo, D., Suseno, Y., \& Yamada, T. (2012). Two-dimensional Threshold-based Cloud Type Classification Using MTSAT Data. 